\title{
MEMÓRIA E HISTÓRIA PARA UMA NOVA VISÃO DA ENFERMAGEM NO BRASIL*
}

Ieda de Alencar Barreira**

BARREIRA, I.A. Memória e história para uma nova visão da enfermagem no Brasil. Rev.latino-am.enfermagem, Ribeirão Preto, v. 7, n. 3, p. 87-93, julho 1999.

Trata-se de um estudo que tem por propósito evidenciar as implicações do conhecimento histórico para a enfermagem, no que se refere à formação de uma consciência crítica e de novas formas de percepção e de apreciação da profissão. Lembrase ainda o potencial da matéria como elemento integrador entre ensino e pesquisa e articulador da graduação com a pósgraduação e que a consolidação de uma linha de pesquisa de história da enfermagem brasileira (HEB) exige o resgate, a preservação e a organização, em todo o país, de fontes primárias de dados, bem como o intercâmbio dos pesquisadores de HEB entre si e com historiadores interessados em estudos afins.

UNITERMOS: história da enfermagem, Brasil, memória, história, ensino, pesquisa

\section{INTRODUÇÃO}

Desde a implantação da enfermagem moderna no país, na década de 20 e até hoje, a História da Enfermagem faz parte do currículo mínimo do curso de graduação. Na verdade, não se sabe bem as razões e os motivos que fizeram com que a disciplina de História da Enfermagem sobrevivesse às várias mudanças efetuadas no currículo mínimo de enfermagem em um período de 70 anos, embora em seus primórdios esta disciplina pareça ter sido utilizada como instrumento para a formação da nascente identidade profissional, para o desenvolvimento de um compromisso perene com a profissão, bem como de busca de uma melhor inserção da enfermagem na sociedade do Rio de Janeiro (BARREIRA et al., 1997). Depois, parece ter continuado a ser utilizada como espaço de doutrinação sobre a mística da enfermagem, suas origens remotas e a contribuição de diversas sociedades para sua evolução. Mas nem as drásticas mudanças impostas pela reforma universitária às escolas de enfermagem no início da década de 70 , nem o advento dos cursos de mestrado, a partir da década de 70, alteraram o ensino da história da enfermagem que, de modo geral, "permaneceu livresco, centrado em vultos e eventos marcantes, pouco crítico, além de distanciado da realidade brasileira" (BARREIRA et al., 1997).

No bojo da grande expansão ocorrida nos últimos anos no campo da história e do renovado prestígio dos estudos históricos em geral, parece haver um crescente interesse da enfermagem pelos aspectos históricos da profissão. O notável incremento que vem ocorrendo da pesquisa acadêmica na área qualifica as escolas de enfermagem a responder a tal demanda. No entanto, para isso torna-se necessária uma reflexão sobre o ensino e a pesquisa da História da Enfermagem Brasileira.

Neste sentido, pretendo evidenciar neste "trabalho esperançoso" (FREIRE, 1992), as implicações do conhecimento histórico para a enfermagem. As divergências passadas e presentes entre os historiadores são apresentadas em linhas muito gerais, de modo a não obscurecer o propósito deste trabalho, qual seja, o de argumentar a favor de um maior envolvimento da comunidade de enfermagem com o estudo de sua história. Por isto, quando o pensamento de alguns autores não está exposto com a riqueza de detalhes e complexidade que eles mereceriam, suas obras estão apenas listadas na bibliografia.

O teor do texto sobre a HEB, corresponde à visão pessoal que venho formando sobre o assunto ao longo do tempo, no convívio com colegas, orientandos e alunos, e a partir do trabalho coletivo no Núcleo de Pesquisa de História da Enfermagem Brasileira da Escola Anna Nery.

\section{MEMÓRIA E PODER}

A memória, como fenômeno individual, corresponde às possibilidades de atualização de certas

\footnotetext{
* Aula inaugural proferida na Escola de Enfermagem de Ribeirão Preto da Universidade de São Paulo, no dia 2 de março de 1998

** Professora Titular do Departamento de Enfermagem Fundamental da Escola de Enfermagem Anna Nery da Universidade Federal do Rio de Janeiro - Núcleo de Pesquisa de História da Enfermagem Brasileira (Nuphebras). Pesquisadora sênior CNPq
} 
impressões ou informações passadas, mediante funções neuropsíquicas complexas, que atuam seletivamente, segundo estímulos externos e motivações internas. A faculdade de memorizar e de recordar é fundamental para o processo ensino/aprendizagem, para o desenvolvimento da personalidade, para a vida de relação e para a integração da pessoa na sociedade. Sua importância pode ser melhor apreciada pelos dramáticos efeitos de sua perda, a amnésia.

O significado da memória pode ser melhor apreendido metaforicamente, através da mitologia indiana do esquecimento e da recordação (ELIADE, 1991), na qual a anamnese aparece como uma forma de conhecimento. Nesta concepção, o esquecimento (amnésia) é comparado ao sono, ao cativeiro, à perda da consciência do self, à cegueira, à ignorância e à morte. Ao contrário, a recordação (anamnesis) é comparada ao despertar, à libertação, à tomada de consciência de sua identidade, ao desvelamento da realidade, à sabedoria e ao renascimento.

Neste sentido é que a desmesurada aceleração do tempo em que vivemos parece vir causando o medo de uma amnésia coletiva, o que vem levando as sociedades a uma busca febril dos vestígios do seu passado, tanto remoto como recente. No entanto, como fenômeno coletivo, a memória também guarda um caráter seletivo. Para Pierre Nora apud LE GOFF (1990), a memória coletiva é "o que fica do passado no vivido dos grupos ou o que os grupos fazem do passado", ou seja, como viveram ou vivem seu passado, como constituíram sua memória coletiva e como esta memória lhes permite fazer face a acontecimentos muito diferentes daqueles que fundam a sua memória, e ainda, encontrar no presente a sua identidade (LE GOFF, 1994).

A memória coletiva, além de uma conquista, é também um instrumento e um objeto de poder. Estando relacionada à formação da identidade social, da solidariedade grupal e da consciência crítica, ela é objeto de manipulação por parte das pessoas e dos grupos que detêm o poder de emprestar visibilidade e prestígio a certos acontecimentos, pessoas, práticas ou idéias e não a outros, em escala local, nacional ou planetária, que são os "formadores de opinião", como os profissionais da comunicação, os políticos, os artistas, bem como os pesquisadores e os professores em geral. Assim é que o domínio das memórias coletivas é objeto de disputa. E se interessa a todos, é vital para os grupos e as sociedades que lutam por reconhecimento.

A memória coletiva é perpetuada através dos documentos de toda natureza, que no entanto, são produzidos por uma determinada sociedade em um dado momento, segundo as relações de poder então existentes. Os efeitos da propaganda e da censura se manifestam tanto nos documentos oficiais, que sempre contam a história dos vencedores, quanto nos silêncios e lacunas dos registros em geral. Por corresponder a um esforço para conservar a memória dos acontecimentos contemporâneos e para fornecer elementos que possibilitem a realização de estudos históricos, o trabalho de documentação considera não somente os documentos oficiais, mas também os depoimentos orais, os arquivos particulares, os álbuns de fotografias, que formam um complexo de conhecimentos não institucionais, e representam a consciência coletiva dos grupos e contrapõem-se a um conhecimento formal que apoia certos interesses de grupos constituídos.

\section{HISTÓRIA COMO CONHECIMENTO}

O ofício do historiador é não somente "o de lembrar o que os outros se esquecem", mas principalmente o de "compreender e explicar porque as coisas deram no que deram e como elas se relacionam entre si". A principal tarefa do historiador "não é julgar, mas compreender, mesmo o que temos mais dificuldade para compreender"; entretanto o que nos dificulta a compreensão "não são apenas nossas convicções apaixonadas, mas também a experiência histórica que as formou". Nosso século 20 é por muitos considerado como o mais dramático e violento da história; nele acentuaramse as desigualdades entre grupos de ricos e de pobres (países e pessoas), dentro de um quadro geral de extraordinário crescimento populacional dos pobres, apesar das guerras e massacres. O enorme progresso da ciência e da tecnologia, em relação dialética com as guerras e com a revolução dos transportes e das comunicações, determinou o encurtamento das distâncias e a aceleração do tempo (HOBSBAUWM, 1995).

Ao final da década de 80, quando havíamos nos acostumado a pensar no mundo em termos da polaridade capitalismo/socialismo, a parte do mundo formada "pelo impacto da Revolução Russa de 1917 se esfacelou", destruindo consigo a relativa estabilidade das relações internacionais, produziu "uma enorme zona de incerteza política, instabilidade, caos e guerra civil" na voragem de conflitos étnicos nacionais e de uma economia transnacional. A essa crise econômica e política, juntase uma crise social e moral. Como contraparte do individualismo radical na economia, observa-se uma radicalização do individualismo social. Além da desestabilização das religiões tradicionais, ocorre a falência não só dos pressupostos filosóficos e dos paradigmas teóricos, mas também dos padrões de relacionamento humano. Inicia-se assim, na virada da última década do século, uma nova era (HOBSBAWM, 1995).

A matéria prima do historiador são os documentos, a partir dos quais, mediante um esforço 
teórico-prático, ele produz o conhecimento histórico. No entanto, a produção do conhecimento é uma prática social e portanto carregada de valores e também sujeita às injunções que condicionam o trabalho dos historiadores, homens e mulheres de seu tempo e que falam de um determinado lugar social, com determinada visão de mundo.

Como em todas as áreas de conhecimento, os historiadores também se agrupam em torno de correntes de pensamento, objetos de estudo, métodos de trabalho, formando grupos específicos e muitas vezes divergentes que debatem com vigor seus pontos de vista, o que faz parte do processo de validação do conhecimento histórico e impulsiona seu avanço. A seguir apresentaremos, em termos muito gerais, as abordagens mais influentes na produção do conhecimento histórico, desde o final do século 19

A abordagem positivista da história pretendia a ressurreição do passado total da humanidade, segundo um critério de verdade histórica, ou seja, a recuperação do passado "tal como realmente aconteceu", segundo uma cronologia e periodização fixas. O documento escrito foi privilegiado, uma vez que poderia atestar a veracidade dos fatos e a objetividade do pesquisador. Esta tendência se fez acompanhar por um grande esforço de coleta e organização dos acervos de arquivos públicos e uma grande expansão dos estudos sobre temas históricos. Nesta época ocorreu a profissionalização do historiador, com a criação de departamentos de história nas universidades e publicação de revistas especializadas em vários países. Esta história factual, de caráter descritivo, baseada nas idéias e decisões de grandes homens públicos, teria um caráter oficial (a história vista de cima, pelas elites dirigentes, principalmente políticas) e definitivo (a Voz da História). Foi esta abordagem que influenciou o ensino da História do Brasil em todos os níveis até pelo menos a década de 70 .

A abordagem marxista da história faz a crítica à abordagem positivista; ao contrário da concepção de um tempo único, linear, cronológico, ocupa-se com o estudo da sucessão descontínua dos diferentes modos de produção; utiliza o método dialético para analisar como as riquezas são produzidas e distribuídas no interior de uma formação social (enfoque sócio-econômico), na qual a ação coletiva dos homens (luta de classes) constitui o motor da história; afirma o caráter científico da história como disciplina, mas considera a produção do conhecimento como um fenômeno social e busca respostas para o agora, segundo um compromisso de transformação da realidade. A influência das diversas correntes marxistas ou neomarxistas impregnou grande parte da produção histórica contemporânea. Exemplo marcante é Eric Hobsbawm, um dos maiores historiadores da atualidade, largamente traduzido para o português e condecorado pelo governo brasileiro em 1996 com a Ordem do Cruzeiro do Sul. Vários dos historiadores brasileiros desta corrente questionaram tanto o ensino como a produção de textos de história do Brasil e Boris Fausto recentemente publicou um tratado didático sobre o assunto.

A assim denominada História Nova tomou grande impulso na França a partir de 1929, com a criação da revista Annales. Esta escola questionou o enfoque positivista de imparcialidade do historiador e da neutralidade do documento escrito, defendendo uma postura crítica frente ao objeto de estudo e às fontes. Os historiadores desse grupo passaram a se interessar por toda a atividade humana, numa perspectiva de "história total". O horizonte dos estudos históricos foi alargado, mediante o estudo das mudanças econômicas e sociais de longa duração. Ao valorizar os costumes e comportamentos e ao dar voz a todos os atores sociais, ensejou a construção de uma história dos vencidos (a história vista de baixo). Ampliou o campo de observação do historiador, propondo novos objetos de estudo (por exemplo: imagens, ritos e mitos, as mentalidades, o presente), novas fontes (por exemplo: memória, biografias, fotos, manifestações artísticas) e novos métodos (por exemplo: entrevistas gravadas, estatística). Considerando a história como uma ciência em construção, seus adeptos não procuraram impor uma teoria a seus pares, convidando-os apenas aos novos métodos de trabalho e à interdisciplinariedade. Os mentores dos Annales foram Marc Bloch e Lucien Febvre e, na geração seguinte, Fernand Braudel. Apesar de representar uma reação ao marxismo ou a algumas de suas versões, muitos de seus historiadores dele receberam influência direta (como Michel Vovelle) ou indireta, como Jacques Le Goff e Georges Duby, grandes divulgadores desse movimento, com obra amplamente traduzida para o português.

A partir da década de 70, a renovação dos estudos históricos, passou a ocorrer em escala mundial. A enorme expansão do campo do historiador levou à sua fragmentação e ao surgimento de inúmeras subdisciplinas, colocando dificuldades à elaboração de sínteses históricas e rompendo o acordo sobre o que constitui a explicação histórica, uma vez que as explicações tradicionais revelaram-se inadequadas ao estudo do comportamento individual e coletivo de curto prazo, criticado como "uma história em migalhas". No entanto, desses novos estudos decorreram "a ampliação considerável dos objetos e das estratégias de pesquisa e a reivindicação do individual, do subjetivo, do simbólico como dimensões necessárias e legítimas da análise histórica" (CARDOSO, 1997).

O ressurgimento do interesse, tanto dos estudiosos como do público em geral pelos temas históricos, que se manifesta nos espaços ocupados no 
movimento editorial, na atividade cinematográfica e na mídia, sob a forma de estudos, documentários, romances históricos e biografias, ocorre no Brasil a partir da década de 80 , com a abertura política.

\section{SIGNIFICADO DA HISTÓRIA PARA A ENFERMAGEM}

Os estudos históricos interessam sobremaneira à enfermagem, pois a construção de uma memória coletiva é o que possibilita a tomada de consciência daquilo que somos realmente, enquanto produto histórico, o desenvolvimento da auto-estima coletiva e a tarefa de (re)construção da identidade profissional. Assim, o desvelamento da realidade mediante o estudo da História da Enfermagem é libertador e permite um novo olhar sobre a profissão.

Neste sentido, vale ressaltar, com Joan Scott, a importância de distingüir a história das mulheres daquela da dos homens, uma vez que "os julgamentos de capacidade estão com freqüência entrelaçados com avaliações de uma identidade social do indivíduo que são irrelevantes à competência profissional" (BURKE, 1992). A análise da condição feminina é pois um elemento central na explicação da trajetória da enfermagem, a partir de uma visão de relações de gênero como formas particulares de relações de poder, ao largo das posições políticas. Uma nova abordagem que parece ser promissora para a enfermagem é a da micro-história, que enfatiza a liberdade de escolha das pessoas comuns, suas estratégias, sua capacidade de explorar as inconsistências ou incoerências dos sistemas sociais e públicos, para encontrar brechas, através das quais possam se introduzir ou frestas em que consigam sobreviver (BURKE, 1992). O movimento da história oral, que vêm sendo amplamente difundido, nas diversas regiões do país, quer ligado às elites, quer ligado aos grupos de pouca visibilidade social, como a enfermagem, oferece a possibilidade da criação de acervos para o uso no ensino e na pesquisa. Outras linhas, recentemente surgidas ou que vêm tendo recentemente um grande desenvolvimento (e de especial interesse para a enfermagem) são as histórias sobre o cotidiano e a vida privada, a sexualidade, a etnia e as religiões.

O interesse pelos estudos de História da Enfermagem é internacional, e mormente na América do Norte já se encontra formalizado e reconhecido como campo de saber, como demonstra a existência de uma Associação Americana de História da Enfermagem e a realização, em junho de 1997, em Vancouver, no Canadá de um Congresso Internacional de História da Enfermagem. Ao contrário, no Brasil, o $1^{\circ}$ Encontro Nacional de História da Enfermagem, ocorrido em Belo Horizonte, há quase quinze anos, com promoção do
Centro de Estudos e Pesquisas da Associação Brasileira de Enfermagem, não teve continuidade.

$\mathrm{Na}$ avaliação da trajetória da enfermagem na sociedade brasileira, é necessário considerar inicialmente que os diversos momentos da vida do país resultaram do jogo de forças políticas, econômicas e ideológicas que também configuraram a organização sanitária de cada época, e que não se estruturaram apenas para atender às necessidades da população, mas resultaram da concorrência entre os vários grupos sociais que formam o sistema produtivo e que apresentavam demandas divergentes entre si.

Também é necessário compreender que se a enfermagem, enquanto prática social, é condicionada pelo contexto onde atua, ela também exerce influência na sociedade em que se insere, segundo as forças sociais em jogo no campo da saúde e, além disso, que sobre as determinações históricas recorta-se a ação coletiva de homens e mulheres e a ação de pessoas que ocupam posições estratégicas, em dado momento ou situação, pois a aceitação de que o indivíduo só pode atuar dentro das condições determinadas pela organização econômica da sociedade e pelo poder político, não elimina a força de certas personalidades nem a imprevisibilidade das opções individuais. Assim, é preciso reconhecer que na história da enfermagem (no passado e no presente) ressaltam figuras que, por sua atuação, se constituem em marcos referenciais.

O modo de inserção das enfermeiras/os no mundo do trabalho, ademais de suas implicações subjetivas, relacionadas ao processo de formação e à vivência de sua prática profissional cotidiana, tem ainda implicações sociais, pois o trabalho que ocupa a maior parte de suas vidas é também um emprego, ou seja, indica seu lugar social na hierarquia de prestígio das profissões. Vale lembrar que a enfermagem, desde suas origens (religiosas e militares) é um saber dominado pelas mulheres e dirigido aos pobres. Como serviço, foi organizado para dar sustentação aos serviços de saúde e para garantir a produção e reprodução da força de trabalho: trabalhadores, mulheres e crianças. Por isto seu reconhecimento no campo da saúde exige "a construção de novas categorias de percepção e de apreciação, ou seja, na emergência de uma nova identidade da enfermeira, diversa daquela aceita pelos detentores do "monopólio da expressão legítima da verdade do mundo social" (BOURDIEU, 1989; ALMEIDA \& BARREIRA, 1997).

\section{AS ESCOLAS DE ENFERMAGEM E A HEB}

Os estudos de HEB, com base em fontes primárias, foram iniciados na década de 60 , por Glete de Alcântara, representante da primeira geração de 
pesquisadoras da área. Antes e depois deste marco, várias enfermeiras se preocuparam em publicar resenhas históricas sobre suas escolas e seus serviços. Na década de 80 surgiram vários estudos acadêmicos de corte histórico-estrutural (CASTRO \& BAPTISTA, 1989), que embora nem sempre tenham utilizado fontes primárias, não só representam o reconhecimento da importância da perspectiva histórica para a enfermagem, mas também, como vários deles foram publicados sob a forma de livro, contribuíram para divulgar este conhecimento para um público maior.

Mais recentemente, a produção pertinente à história da enfermagem se tem repartido, com vantagem para a produção de seu saber, como observou VAINFAS (1997) referindo-se à historiografia atual, em diferentes escalas ou pontos de observação e adotando tanto uma postura explicativa como a descrição do detalhe cultural, ou seja a(s) realidade(s) e suas representações.

Para que se possa chegar à fase de trabalhos de síntese histórica ou até à (re)construção de uma História da Enfermagem Brasileira, é necessário acumularmos uma massa de pesquisas, que abranjam várias temáticas e recortes, e ainda, o maior desafio, que não se restrinjam às regiões de maior produção científica. Vale notar que entre nós o livro texto mais divulgado sobre o assunto, foi escrito há quase meio século por Waleska Paixão, que à época dedicou apenas vinte e sete páginas à enfermagem brasileira.

Além disso, o desenvolvimento da pesquisa na área da HEB depende da existência e da qualidade das fontes documentais, as quais vêm sendo sistematicamente destruídas. Precisamos proteger nossa memória. Precisamos nos empenhar na recuperação, produção e organização de fontes para a pesquisa. Precisamos de quem elabore monografias, crônicas, memórias, compilações e históricos, o que é um trabalho de enormes méritos e que exige grandes doses de acuidade intelectual, sensibilidade estética, capacidade de trabalho, perseverança e honestidade científica. Exemplo notável é o documentário sobre a Associação Brasileira de Enfermagem, elaborado por Anayde Corrêa de Carvalho na década de 70 (CARVALHO, 1976). As bibliotecas, os arquivos e os museus, além de repositórios desses documentos, são lugares de produção e difusão do conhecimento. No que se refere aos últimos, vale citar o Centro de Documentação da Escola Anna Nery e o Museu da Escola de Enfermagem da USP-São Paulo.

A criação de núcleos de pesquisa de HEB nas escolas de enfermagem é decisiva ao incremento da produção científica e à sua difusão. A consolidação e o reconhecimento de uma linha de pesquisa de HEB de corte nacional exigem precondições tais como a criação ou fortalecimento de centros de documentação para a preservação e organização de fontes primárias, que favoreçam a renovação do ensino e da pesquisa em HEB, tendo em vista inclusive a articulação dos programas oferecidos nos diferentes níveis e sob a forma tanto de conteúdos obrigatórios como de disciplinas eletivas, que apoiem tanto pesquisas de natureza histórica como favoreçam a adoção de uma perspectiva histórica que possa enriquecer outras disciplinas ou outros estudos, num enfoque interdisciplinar.

$\mathrm{Na}$ Escola de Enfermagem Anna Nery a construção dessa linha iniciou-se na virada da década de 80 para 90, em estreita ligação com o curso de doutorado, o Centro de Documentação e o Núcleo de Pesquisa de História da Enfermagem Brasileira (Nuphebras). Entre os serviços prestados pelo Nuphebras, conta-se um cadastro de seus pesquisadores e projetos de pesquisa correspondentes, concluídos ou em andamento. Esses estudos se concentram no período compreendido a partir da segunda metade do século 19, inserindo-se portanto na história contemporânea, na história do tempo presente ou história atual. Há uma busca das raízes que dirige alguns deles para as influências do cristianismo e das guerras no desenvolvimento da enfermagem (na Inglaterra, nos EUA e no Brasil), num contexto de forte presença da Igreja católica nos setores saúde e educação da sociedade brasileira, bem como os desdobramentos no campo da enfermagem das alianças e conflitos entre Igreja e Estado, desde o segundo Império. Outros estudos voltam-se para as condições em que surgiu a enfermagem moderna na Inglaterra e sua difusão para os EUA, bem como os nexos entre esta e a enfermagem brasileira.

Também têm sido objeto de estudos as formas de constituição e de difusão da enfermagem moderna no Brasil, a importância das políticas sociais, do desenvolvimento da tecnologia e das formas de organização do trabalho, e a trajetória das escolas de enfermagem no contexto de um processo de secularização e de cientificização. As categorias condição feminina, raça e classe social têm sido relacionadas entre si e à inserção da carreira da enfermagem na universidade e nos serviços de saúde, em concorrência com as demais categorias existentes no campo da saúde, a cada época. Os elementos constitutivos da ideologia da enfermagem e da mística da profissão vêm sendo analisados em relação à reprodução social das categorias de enfermagem. Também tem sido abordada a temática das entidades de classe (associativa e sindical). Tanto os condicionantes históricos como o imaginário social, que são aspectos diferentes e complementares de uma mesma realidade, têm sido abordados por esses estudos, e às vezes considerados simultaneamente.

O centro dinâmico do Nuphebras, nos pouco mais de quatro anos de sua existência vem sendo as reuniões semanais, das quais participam sistematicamente os três membros de sua diretoria colegiada, outras professoras 
pesquisadoras, bem como alunos de pós-graduação e bolsistas dos projetos integrados apoiados pelo CNPq. Nestas reuniões são programadas as atividades de ensino e pesquisa de cada semestre, inclusive a apresentação de projetos e sub-projetos em eventos científicos e a elaboração de relatórios técnicos relativos aos projetos integrados. Para os alunos de graduação, o Nuphebras oferece, em caráter obrigatório: um seminário de apresentação dos resultados das pesquisas registradas no Nuphebras, um estágio supervisionado no Centro de Documentação, e a coordenação de um simpósio sobre um tema da história da enfermagem brasileira, em colaboração com os formandos (a avaliação discente dessas atividades é representada sob a forma de descoberta); a partir do próximo semestre serão oferecidas também disciplinas eletivas. Para os alunos de pósgraduação há o oferecimento de quatro disciplinas eletivas (nível de mestrado e de doutorado), sobre os fundamentos teóricos e práticos da pesquisa histórica que toma como objeto a enfermagem, bem como seus aspectos operacionais. Mestrandos e doutorandos em processo de elaboração de teses sobre temas de história da enfermagem, junto com as pesquisadoras do Núcleo e com os bolsistas do $\mathrm{CNPq}$, formam uma equipe de docentes e alunos que, no desenvolvimento de suas atividades de ensino, articulam a iniciação à pesquisa do aluno de graduação de modo geral, com a iniciação científica dos bolsistas, com o preparo para o ingresso no curso de mestrado e com o processo de elaboração de teses (BARREIRA \& BAPTISTA, 1998).

O intercâmbio com os historiadores, cuja crítica é imprescindível ao avanço de nossos estudos, se vem fazendo principalmente através da participação de professores pesquisadores da própria UFRJ, da UFF, da Casa de Oswaldo Cruz, da Fundação Getúlio Vargas e também da USP, em bancas de exame (de teses e dissertações, de qualificação ou mesmo de apresentação de projetos) e em alguns casos ocorre sua participação como co-orientadores.

\section{CONSIDERAÇÕES FINAIS}

A luta por uma concepção e formulação mais elaborada de um futuro coletivo impõe um esforço crítico e reflexivo sobre os caminhos que nos trouxeram à realidade presente, e sobre as possibilidades de ruptura com os modelos vigentes de visão e de classificação do espaço social, ou seja “de poder fazer ver e fazer crer". E aqui se coloca a questão da esperança, que a incerteza do devir histórico nos permite.

Uma melhor compreensão da trajetória da nossa profissão, necessária à formação de uma consciência crítica, além do conhecimento da história da enfermagem brasileira, que faz parte da cultura profissional de cada qual, depende também do interesse e da consciência que nós, mulheres e homens de algum modo envolvidos, tivermos das relações passado/presente, o que faz com que valorizemos nossos papéis históricos, como observadores atentos dos sinais de nossa época, como pessoas que nos empenhamos em formar uma opinião esclarecida, como atores que participam do movimento da história e como estudiosos que pretendem contribuir para a compreensão do que nos ocorreu e do que nos ocorre, posto que (parafraseando Hobsbawm), somos parte dessa história e ela é parte de nós.

\section{MEMORY AND HISTORY FOR A NEW VIEW OF NURSING IN BRAZIL}

This study aims at evidencing the involvement of the historic knowledge to nursing, regarding to development of a critical conscience and new ways of perception and appreciation of the profession. Authors emphasize the potential of the subject to integrate teaching and research as well as to articulate the undergraduate and graduate programmes and in the consolidation of a research line of brazilian nursing history $(H E B)$, demanding the preservation in the whole country of data sources, and the interchange between HEB researchers and historians who have interests on studies like this.

KEY WORDS: nursing history, Brazil, memory, history, teaching, research

\section{MEMORIA E HISTORIA PARA UNA NUEVA VISIÓN DE LA ENFERMERÍA EN BRASIL}

Se trata de un estudio que tiene como propósito evidenciar las implicaciones del conocimiento histórico para la enfermería en lo relacionado con la formación de una consciencia crítica y de nuevas formas en la percepción y en la apreciación de la profesión. También se resalta el potencial de la materia como elemento integrador entre la enseñanza y la investigación y articulador del pregrado con el posgrado y que la consolidación de una línea de investigación de Historia de la Enfermería Brasileña exige el rescate, la preservación y la organización en todo el país, de fuentes primarias de datos, así como también el intercambio de investigadores de HEB (Historia de Enfermería Brasileña) entre si y con historiadores interesados en estudios afines. 


\section{REFERÊNCIAS BIBLIOGRÁFICAS}

01. ALMEIDA, M.C.P.; BARREIRA, I.A. Mestrados e doutorados em enfermagem. In: CHOMPRÉ, R.R. et al. (orgs). Educação de enfermagem na América Latina. Belo Horizonte: Escola de Enfermagem da UFMG/Fundação Kellogg, 1998. (no prelo).

02. BARREIRA, I.A.; BAPTISTA, S.S. O processo de construção de uma linha de pesquisa em história da enfermagem brasileira: contribuição, perspectivas e desafios / Apresentado no $6^{\circ}$ Colóquio Pan-Americano de Enfermagem, em Ribeirão Preto, de 20 a 22 de maio de 1998/.

03. BARREIRA, I.A. et al. Renovação no ensino e na pesquisa de história da enfermagem pela integração graduação/pós-graduação. Revista Enfermagem da UERJ, Rio de Janeiro, v. 5, n. 2, p. 487-494, dez. 1997.

04. BOURDIEU, P. O poder simbólico. Lisboa: Difel, 1989.

05. BURKE, P. A escrita da história: novas perspectivas. São Paulo: Editora da Universidade Estadual Paulista, 1992.

06. CARDOSO, C.F. História e paradigmas rivais. In: CARDOSO, C.F.; VAINFAS, R. Domínios da história: ensaios de teoria e metodologia. Rio de Janeiro: Campus, 1997. p. 01-23.

07. CARVAlHO, A.C. Associação Brasileira de Enfermagem (1926-1976): documentário. Brasília: ABEn, 1976.

08. CASTRO, I.B.; BAPTISTA, S.S. (orgs.). Livros de enfermagem: Brasil (1916-1988). Rio de Janeiro: ABEn/CEPEn: CNPq, 1989.
09. Eliade, M. Mito e realidade. São Paulo: Perspectiva, 1991.

10. FREIRE, P. A pedagogia da esperança. Rio de Janeiro: Paz e Terra, 1992.

11. HOBSBAWM, E. A era dos extremos: o breve século 20 (1914-1991). São Paulo: Companhia das Letras, 1995.

12. LE GOFF, J. A história nova. São Paulo: Martins Fontes, 1990.

13. História e memória. 3. ed. Campinas: Editora da Unicamp, 1994.

14. VAINFAS, R. Caminhos e descaminhos da história. In: CARDOSO, C.F.; VAINFAS, R. Domínios da história: ensaios de teoria e metodologia. Rio de Janeiro: Campus, 1997. p. 441-449.

\section{BIBLIOGRAFIA CONSULTADA}

01. ALCÂNTARA, G. A enfermagem moderna como categoria profissional: obstáculos à sua expansão na sociedade brasileira. Ribeirão Preto: Universidade de São Paulo: ABEn, 1966.

02. ASSOCIAÇÃO BRASILEIRA DE ENFERMAGEM. Centro de Estudos e Pesquisas (CEPEn). 1 ${ }^{\circ}$ Encontro Nacional de História da Enfermagem: programa. Belo Horizonte, 1984 (fotocópia).

03. MORAES NETO, G. FH concede a Hobsbawm a Ordem do Cruzeiro do Sul. O Globo, Rio de Janeiro, 10 fev. 1996.

04. PAIXÃO, W. Páginas da história da enfermagem. 3. ed. Rio de Janeiro: Bruno Buccini, 1963. 